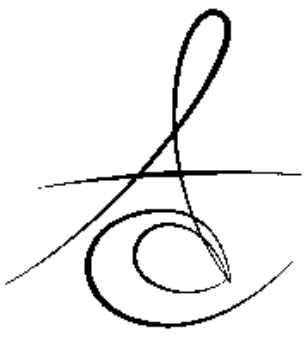

\title{
ORAL MALİGN MELANOM'UN REZEKSİYONU SONUCU OLUŞAN MAKSİLLER DEFEKTİN PROTETÍK TEDAVİSİ: OLGU SUNUMU
}

\section{THE PROSTHETIC TREATMENT OF MAXILLARY DEFECT RESULTING IN RESECTION OF ORAL MALIGNANT MELANOM: CASE REPORT ${ }^{*}$}

\author{
Dr. Öğr. Üyesi Hatice ÖZDEMİR*
}

\author{
Lütfü İhsan ALADAĞ**
}

Makale Kodu/Article code: 2867

Makale Gönderilme tarihi: 26.05.2016

Kabul Tarihi: 09.08.2016

\section{ÖZET}

$\mathrm{Bu}$ olgu sunumunun amacl, malign melanomun rezeksiyonu sonucu oluşan maksiller defektin protetik tedavisini sunmaktır. Malign melanom, oral kavitede nadir olarak görülen kötü prognoza sahip agresif bir tümördür. Kliniğimize başvuran 60 yaşındaki kadın hastaya total maksillektomi yapıldığı görüldü. Radyoterapiden 8 ay sonra protez işlemlerine başlandı. Hastanın üst çenesine yumuşak akrilikten bulbu olan obturatör yapıldı. Kısmi dişsiz alt çenesine de metal iskelet alt yapılı parsiyel protez yapıldı. Obturatörün bulb kısmının protez tutuculuğunu olumlu yönde etkilediği görüldü. Protetik tedavi sonrası hastanın estetik, fonetik ve psikolojik problemlerinin ortadan kalktığı görüldü. 3 ay sonra yapılan kontrolde hastanın protezinden memnun olduğu öğrenildi.

Anahtar Kelimeler: Malign melanom, maksiller defekt, protetik tedavi

\section{GİRİ̧̧}

Malign tümörlerin yaklaşık olarak $\% 5^{\prime}$ i oral ve maksillofasiyal bölgede; oral bölgedeki malign tümörlerin de \% 9 kadarı sert damakta ve \% 12' si de dişetinde görülmektedir. ${ }^{1,2}$ Malign melanomlar, oral kavitede görülen nadir lezyonlardır ve rapor edilen vakaların \% 80'inde çoğunlukla maksiller gingiva, sert damak ve alveol kretinde görülmekte, yaklaşık \% 20'sinde ise mandibulada lokalize olarak görülmektedirler. ${ }^{3-6}$

Malign melanomların birçoğu normal mukoza görünümüne sahiptir. ${ }^{7}$ Oral melanomların ağız içi klinik bulgularında; asimetrik ve düzensiz sınırlı 6 mm'den

\section{ABSTRACT}

The purpose of this case report is to present the prosthetic treatment of maxillary defect developed after resection of malignant melanom. Malignant melanoma is aggressive tumors with a poor prognosis are rarely seen in the oral cavity. We experienced that 60 year old female patient consultationed our clinic operated with total maxillectomy. The prosthetic treatment was started after 8 month from radiotherapy. The upper jaw of patient was made an obturator with bulb made from soft acrylic. The partial edentulous lower jaw of patient was made partial prosthesis with metal framework, too. The bulb part of obturator had a positive effect in retantion of prosthesis. The esthetics, phonetic and psychological problems of patients were remowed after prosthetic treatment. The patient said to please with prosthesis in conrol made after 3 month.

Keywords: Malignant melanom, maxillary defect, prosthetic treatment

büyük, düz ya da yüksek seviyeli lezyonlar görülür., 3,8 Tedavi yöntemini ise cerrahi ve/veya radyoterapi oluşturmaktadır. ${ }^{9}$ Yapılan cerrahi operasyonlar sonucunda ilgili bölgede defekt oluşmaktadır. Maksiller bölgedeki tümörlerin cerrahi tedavisi sonucu oluşan defektler hastada; konuşma, estetik ve fonksiyonel bozukluklara sebep olmaktadır. ${ }^{10}$ Oluşan bu bozukluklar kişinin yaşam kalitesini düşürmektedir ve bu yüzden tümörleri tedavi etmedeki ilk amaç; hastalığı elimine etmek ve bireyin yaşam kalitesini artırmak olmalıdır. ${ }^{11}$

Diş hekimliğinde; benign ve malign tümörlerin cerrahi olarak rezeke edilmesi, konjenital malformasyonlar ve travmatik sebepler ile maksillanın kısmi ya

\footnotetext{
* Atatürk Üniversitesi Diş Hekimliği Fakültesi, Protetik Diş Tedavisi AD, Erzurum.

${ }^{* *}$ Emekli Öğretim Üyesi.
} 
da total olarak çıkartılması sonucu oluşan, oral ve nazal boşlukları birleştirerek birtakım komplikasyonlara yol açan ve cerrahi olarak kapatılamayan defektleri tıkayan apareylere "obturatör" denilmektedir. ${ }^{12}$

Obturatör yapımında karşılaşılan en büyük sorun yeterli desteğin olmamasından dolayı retansiyonun sağlanamamasıdır. Özellikle total maksiller rezeksiyonlu hastalarda proteze destek ve retansiyon sağlayacak olan alveol kretleri ve dişlerin olmaması büyük problem yaratmaktadır. ${ }^{13,14}$ Total maksiller rezeksiyonlu hastalarda defektin içinden protez için destek sağlanabilmektedir. Göz tabanı, burun septumu, processus pterygoideus'un iç yan laminası destek olarak faydalanılabilecek anatomik yapılardır. ${ }^{15,16}$ Maksillektomi sonrası yapılan obturatörlerin tutuculuğunu sağlayan, lateral hareketlerde stabilizasyona katkıda bulunan ve konuşmada, seslerin oluşumunda rezonans açısından önemli bir parça olan kısma "bulb" adı verilir. Bulblar yapıldıkları malzemeye göre; sert, yumuşak ve sertyumuşak olmak üzere üçe ayrllırlar. Obturatörlerde yapılan bulb ile hastanın fonksiyonunu ve fonasyonunu iyileştirmek, kaybedilen dokuların yerini alarak tıkaç görevi görmesi amaçlanır. Bulb, çiğneme sırasında göze baskı yapacak kadar yüksek ve ağızın açılma miktarı sınırı ise buna engel olacak kadar geniş ve yüksek olmamalıdır. ${ }^{17-21}$

$\mathrm{Bu}$ çalışmada, malign melanom sonucu total maksiller rezeksiyon yapılan bir hastaya uygulanan hollow yumuşak bulblu obturatör sunulmuştur.

\section{OLGU SUNUMU}

Atatürk Üniversitesi Diş Hekimliği Fakültesi Protetik Diş Tedavisi Anabilim Dalı kliniğine başvuran total maksillektomi yapılmış 60 yaşındaki bayan hastanın anamnezinde malign melanom tanısıla operasyon geçirdiği ve sonrasında da radyoterapi gördüğü öğrenildi. Ağız içi muayenede, hastanın üst çenesinin total dişsiz, alt çenesinin parsiyel dişsiz olduğu ve yumuşak damağının da operasyon sırasında alınmadığı görüldü (Şekil 1). Ağız dışı muayenede, sağ ve sol yanakla üst dudağın hafif çökük olduğu ve üst total dişsizliğe bağı olarak alt yüz yüksekliğinde azalma görüldü. Hastanın anamnezi alındıktan sonra radyoterapisini uygulayan uzman doktordan protez yapımıyla ilgili konsültasyon istendi. Dişsizlik ve defekte bağlı olarak hastada; çiğneme, konuşma ve yutkunma problemleri belirlendi. Konsültasyon sonucu belli olana kadar hastadaki mevcut bu problemleri azaltmak için cerrahi operasyon sırasında yapılan ve uzun bir süre geçtiği için dokularla uyumunu yitiren beslenme plağı, yumuşak astar maddesiyle beslenerek hastanın tekrar kullanması sağlandı. Hastanın beslenme plağıyla çiğneme yapamaması ve cerrahi işlem sonrası nasal sonda takılmamasından dolayı etkin beslenememesi nedeniyle radyoterapi uzmanının verdiği onayla radyoterapiden 8 ay sonra protez yapımına başlandı.

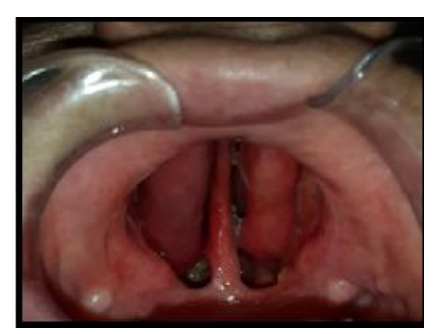

Şekil 1. Defekt bölgesinin ağız içi görünümü

İlk seansta, hastanın ağzına uygun büyüklükteki üst total, alt parsiyel metal hazır kaşıklarla birinci ölçü alındı. Üst çeneden ölçü alııırken ölçü maddesinin defekt bölgesindeki boşluklara kaçmaması için önce vazelinli gazlı bezle kapatıldı. Üst çeneden alınan ölçüye beyaz alçı, alt çeneden alınan ölçüye de sert alçı dökülerek modeller elde edildi. Alt çene modeli metal iskelet planlaması yapıldıktan sonra diş laboratuarına gönderildi. Üst çene modeli üzerine basplaktan özel ölçü kaşığı hazırlandı. İkinci seansta, özel ölçü kaşığı hasta ağzında kontrol edilerek kenar uyumları değerlendirildi. Vestibül sulkuslar olmadığı için sadece postdam bölgesi stenç ile uzatılarak hasta ağzında kontrol edildi. Aynen ilk ölçüde olduğu gibi yine vazelinli gazı bezle defekt bölgesi kapatılıktan sonra irreversible hidrokolloid ölçü maddesiyle ikinci ölçü alındı. Hidrokolloid ölçü maddesi kullanılmasındaki amaç, defekt bölgesindeki andırkatlı bölgelerin, ölçü maddesinin esnek yapısından dolayı ölçü deforme olmadan modele yansıtılmasıdır. Alınan ölçüye sert alçı dökülerek üzerinde obturatör yapılacak esas model elde edildi (Şekil 2).

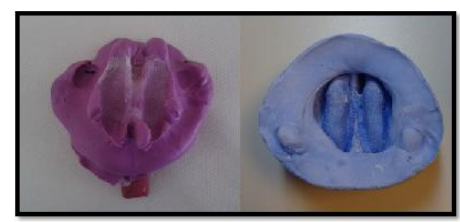

Şekil 2. Üst çeneden alınan ikinci ölçü ve modeli

Elde edilen model üzerinde basplaktan kaide hazırlanarak kapanı̧̧ alma işlemine geçildi. Üst çene modeli üzerine ve alt metal iskelet üzerine mum duvarlar hazırlandıktan sonra hasta ağzında kontrol

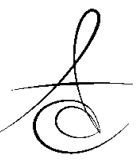


edilerek dikey boyutu belirlendi. Sonra çeneler arası yatay sentrik ilişkide belirlenerek mum duvarlar sabitlenip ağızdan çıkarıldı. Hastanın ağzındaki mevcut dişlerine uygun renkte ve çenesine uygun büyüklükte diş seçilerek dizim için diş laboratuarına verildi. Diş diziminden sonra hasta ağzında prova yapılarak estetik ve kapanış açısından değerlendirildi (Şekil 3). Dişli provada herhangi bir sorun görülmediği için protezler bitime verildi.

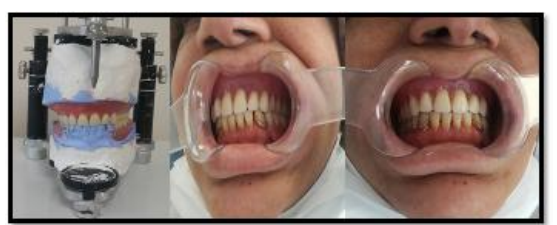

Şekil 3. Diş diziminin artikülatör ve ağızdaki görünümü

Alt çene protezi için rutin laboratuar işlemleri uygulanarak protez bitirildi. Üst çene protezinde de, obturatörün bulb kısmının yumuşak astar maddesinden olması planlandığı için öncelikle bu kısma sıcakla polimerize olan yumuşak astar maddesi yerleştirilip sınırları kontrol edildi. Tüm andırkatlı bölgelerin yumuşak astar maddesiyle kapandığı gözlendikten sonra, diğer kısımlara sıcak akrilik tepilerek rutin protez bitim işlemlerine devam edildi (Şekil 4).

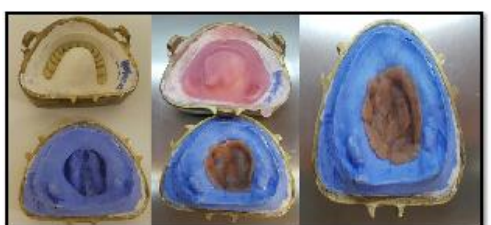

Şekil. 4. Obturatörün yumuşak bulb kısmının muflada tepim işlemleri

Protezlerin tesviye ve cila işlemlerinden sonra akriliğin bünyesinde bulunan artık monomerin uzaklaşması için protezler bir hafta boyunca suda bekletildi. Bu süre içerisinde belirli aralıklarla su değiştirildi.

Son seansta bitmiş protezler hasta ağzına takılarak kontrol edildi(Şekil. 5). Andırkat bölgelerine giren yumuşak astardan yapılmış bulbun, protez tutuculuğuna önemli derecede olumlu etki yaptığı görüldü. Hastaya protezlerini takıp çıkarması gösterilip, bakım ve kullanımı ile ilgili bilgi verildikten sonra 1 hafta sonra kontrole çağrıldı. Kontrolde hastanın protezinden memnun olduğu öğrenildi. 1 ay sonra yapılan kontrolde, protezlerini düzenli kullanan hastanın fonksiyon, estetik, fonasyon ve psikolojik olarak olumlu yönde etkilendiği gözlemlendi (Şekil 6).

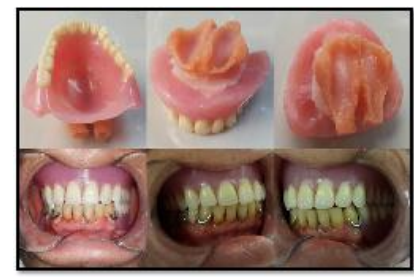

Şekil 5. Obturatörün bitmiş hali ve ağız içi görünümü

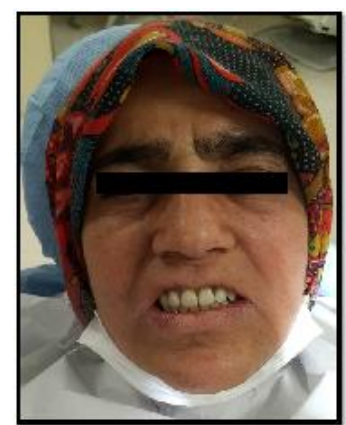

Şekil 6. Hastanın profilden görünümü

\section{TARTIŞMA}

Maksillektomi sonucu oluşan defektlerin protezle rehabilitasyonuna karar verirken göz önüne alınması gereken faktörler vardır. Bunlar; defekt alanının büyüklüğü, andırkatlı bölgeler, yumuşak damağın olup olmaması, hastanın radyoterapi görüp görmemesi, hastanın genel sağlık ve psikolojik durumudur. Bu faktörleri göz önünde bulundurarak kliniğimize başvuran hastaya, elastik silikon esaslı materyalden bulbu olan obturatör yapıldı.

Obtüratör yapımında özellikle bulb kısmının yapımında elastik silikon esaslı materyallerin kullanıması, sert akrilik rezinlere oranla daha iyi bir tutuculuk sağlar ve daha az irritasyon olusturur. Ayrıca, yumuşak bulblu obtüratörler daha hafiftir ve kolayca takılıp çıkarılabildikleri için protezin bakım ve temizliği daha kolay yapılır. Elastik silikon esaslı materyallerin bu avantajlarına rağmen zamanla elastikiyetlerini kaybederek sertleşme gibi dezavantajları da vardır. Bunun sonucunda da obturatörün tutuculuğu azalır. ${ }^{21,22}$ Sunulan vakada hasta sık sık kontrole gelebileceğini bildirdiği için yumuşak bulblu obtüratör yapılarak tutuculuğun artırılması ve radyoterapi sonucu hassas olan ağı dokularında oluşabilecek irritasyonun minimalize edilmesi amaçlandı. Yapılan kontrollerde de protezin tutuculuğunun gayet iyi olduğu ve irritasyonun olmadığı gözlemlendi.

Maksillektomiden sonra yeterli fonksiyonel ve estetik rehabilitasyon için stabil obturatör protezleri

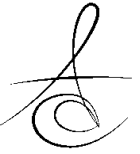


gereklidir. ${ }^{23}$ Obturatörlerin ağır olması karşılaşılan problemlerden biridir. Bu problemi azaltmak için bulb içinde boşluk oluşturmak gibi çesitli yöntemler kullanılabilir. ${ }^{24}$ Ancak vakamızda defektin derinliğinden ziyade genişiliği fazla olduğu için hafif damak kubbesi derinleştirilerek ve bulbun büyük bir kısmı elastik silikon esaslı materyalden yapılarak protezin hafif olması sağlandı. Böylelikle bulbun içini boşaltmaya da gerek kalmadı.

Total maksillketomi yapılmış hastalara yapılan hollow bulb obturatörler, hastaların çiğneme, konuşma ve yutkunma fonksiyonlarını sağlarlar. Havuzlu obturatörlerle karşılaştırılacak olursa daha hijyeniktir; çünkü, bulbun medial, lateral, ön ve arka duvarlarının bulunmasına karşın tavanının bulunmaması burada sekresyon birikimine ve kötü koku oluşmasına yol açar. ${ }^{17,25}$ Sunulan vakada hollow bulb obturatör yapılarak yukarıda bahsedilen olumsuzluk önlenmiş olundu.

Daha hijyenik olması, hafif olması nedeniyle hastanın fonksiyon sırasında daha rahat olması, tutuculuğunun daha iyi olması nedeniyle çevre dokularda daha az stres oluşturacağı düşünülerek yapılan hollow yumuşak bulblu obturatör ile hastanın çiğneme, konuşma ve yutkunma gibi fonksiyonları geri kazandırımış ve hastanın üst total ve alt parsiyel dişsizliği de giderilerek estetik görünüm iyileştirilmiştir. Böylelikle hastanın yaşam kalitesi arttııımışır. Yapılan kontroller sonucu, protezin tutuculuk ve stabilitesinin yeterli olduğu ve hastanın protezini rahatlıkla kullandığı rapor edilmiştir.

Hatice Özdemir: ORCID ID: 0000-0001-8512-0471 L.İhsan Aladağ ORCID ID: 0000-0001-7380-1472

\section{KAYNAKLAR}

1. Rieger J, Wolfaardt J, Seikaly H, Jha N. Speech outcomes in patients rehabilitated with maxillar $y$ obturator prostheses after maxillectomy: a prospective study. Int J Prosthodont 2002;15:13944.

2. Kreeft AM, Krap M, Wismeijer $D$, Speksnijder $C M$, Smeele LE, Bosch SD, Muijen MS, Balm AJ. Oral function after maxillectomy and reconstruction with an obturator. Int J Oral Maxillofac Surg 2012;41:1387-92.
3. Aguas SC, Quarracino MC, Lence AN, Lanfranchi Tizeira HE. Primary melanoma of the oral cavity: ten cases and review of 177 cases from literature. Med Oral Patol Oral Cir Bucal 2009;14:E265-71.

4. Lourenco SV, Bologna SB, Colucci F, Neto CF, Montenegro FL, Nico MM. Oral mucosal melanoma of the mandibular gingiva: a case report. Cutis 2010;86:89-93.

5. Tucci R, Aburad De Carvalhosa A, Anunciacao G, Daumas Nunes $F$, Dos Santos Pinto D, Jr. Late diagnosis of a primary oral malignant melanoma: a case report. Minerva Stomatologica 2010;59:55-9.

6. Gondivkar SM, Indurkar A, Degwekar S, Bhowate R. Primary oral malignant melanoma-a case report and review of the literature. Quintessence Int 2009;40:41-6.

7. Umeda $M$, Komatsubara $H$, Shibuya $Y$, Yokoo S, Komori T. Premalignant melanocytic dysplasia and malignant melanoma of the oral mucosa. Oral oncology 2002;38:714-22.

8. Bujas T, Pavic I, Prus A, Marusic Z, Balicevic D. Primary oral malignant melanoma: case report. Acta Clinica Croatica 2010;49:55-9.

9. Itami J, Uno T, Aruga M, Ode S. Squamous cell carsinoma of the maxillary sinus treated with radiation therapy and concervative surgery. Cancer 1998;82:104-7.

10. Keyf F. Obturator prostheses for hemimaxillectomy patients. J Oral Rehabil 2001;28:821-9.

11. Lucas RB. Ameloblastoma. In: Pathology of the Oral Diseases, $4^{\text {th }}$ ed. London: Churchill Livingstone, 1984:31-60.

12. Akay C, Yaluğ S. Kısmi maksillektomi yapılmış hastaların bukkal uzantılı obturatör ile protetik rehabilitasyonu: Vaka raporu. Atatürk Üniv Diş Hek Fak Derg 2014;24:278-82.

13. Taylor TD, Fyler A, LaVelle WE. Alternative obturation for the maxillectomy patient with severely limited mandibular opening. J Prosthet Dent 1985;53:1-6.

14. Minsley GE, Nelson DR, Rothenberger SL. An alternative method for fabrication of a closed hollow obturator. J Prosthet Dent 1986;55:485-90.

15. Wu YL, Schaaf NG. Comparison of weight reduction in different designs of solid and hollow obturator prostheses. J Prosthet Dent 1989;62:214-7.

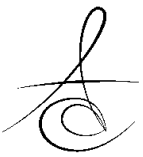


16. Devlin H, Barkar GR. Prosthetic rehabilitation of the edentolous patient requiring a partial maxillectomy. J Prosthet Dent 1992;67:223-30.

17. Özdemir AK, Coşkun A, Tunalı A, Yaluğ S. Maksiler rezeksiyonların protetik obturasyonu. Cumhuriyet Üniv Diş Hek Fak Derg 1998;1:73-7.

18. Yazıcıoğlu H. Adheziv ve adheziv temizleme ajanının yumuşak akril ve silikonların bazı fiziksel özelliklerine etkisi. T Klin Diş Hek Bil Derg 2001;7:35-40.

19. Yazıcıoğlu $H$, Yaluğ $S$, Akalın MR. İki farklı obturatör yapım yöntemine göre dişler arasındaki boyutsal farkılığın değerlendirilmesi. Atatürk Üniv Diş Hek Fak Derg 2001;11:28-32.

20. Yazıcıoğlu $H$, Yaluğ $S$, Akalın MR. Havuzlu ve balonlu obturatörlerde kaide plağında görülen boyutsal değişikliklerin incelenmesi. Ondokuz Mayıs Üniv Diş Hek Fak Derg 2001;5:40-3.

21. Shimodaira K, Yoshida H, Mizukami M, Funakubo T. Obturator prosthesis conforming to movement of the soft palate: a clinical report. J Prosthet Dent 1994;71:547-51.

22. Özdemir H, Aladağ Lİ. Sonradan kazanılmış bir maksiller defektin protetik obturasyonu: Bir olgu sunumu. Ata Üniv Diş Hek Fak Derg 2011;Suppl 4:122-27.

23. Albrektsson T, Zarb G, Wortrhington $P$, et al. The long-term efficacy of currently used dental implants: A review and proposed criteria of success. Int J Oral Maxillofac Implants 1986;1:11.

24. Yalug S, Nalbant L. Bir bukkal uzantılı obtüratör yapımı: Cumhuriyet Üniv Dis Hek Fak Derg 1998;1:78-80.

25. Araş E. Bukkal uzantılı obturatör yapım yöntemi. Ankara Üniv Diş Hek Fak Derg 1984;11:245-56.

\section{Yazışma Adresi}

Dr. Öğr. Üyesi Hatice ÖZDEMİR, Atatürk Üniversitesi Diş Hek. Fak. Protetik Diş Tedavisi A.D

TIf: 04422311783

e-mail: dentist_hatice@hotmail.com 